\section{Aktif Öğrenmeye Dayalı Etkinliklerin Sınıf Öğretmen Adaylarının Sürdürülebilir Çevreye Yönelik Tutumlarına, Olumlu Davranışlarına ve Çevre Tutumlarına Etkisi}

\author{
Gülfem Muşlu Kaygısız ${ }^{1}$
}

Türk Eğitim Bilimleri Dergisi

Makale Türü: Araştırma

Makale Geliş Tarihi: 24.01.20

Makale Kabul Tarihi: 21.03.20

Makale Yayın Tarihi: 26.06.20

\title{
Öz
}

$\mathrm{Bu}$ araştırmada aktif öğrenmeye dayalı öğretimin sınıf öğretmen adaylarının sürdürülebilir çevreye ilişkin tutumlarına, çevreye yönelik olumlu davranışlarına ve çevreye yönelik tutumlarına etkisinin olup olmadığını belirlemektir. Çalışma 2017-18 öğretim yılı bahar döneminde "Çevre Bilim ve Eğitimi" dersinde 34 sınıf öğretmen adayı ile yürütülmüştür. Ayrıca 2019-2020 güz döneminde izleme testi gerçekleştirilmiştir. Araştırma verileri Sürdürülebilir Çevreye Yönelik Tutum Ölçeği, Çevreye Yönelik Olumlu Davranış Ölçeği ve Çevreye Yönelik Tutum Ölçeği ile toplanmıştır. Araştırma zayıf deneysel desenlerden tek grup ön test-son test deseniyle gerçekleştirilerek analizler SPSS.22 programiyla yapılmıştır. Öğretmen adaylarıyla tartışmaya dayalı olarak çevre sorunları irdelenmiş, adayların çevreye ilişkin bazı filmleri analiz etmeleri istenmiş ve çeşitli alan gezileri düzenlenmiştir. Araştırmada öğretmen adaylarının çevreye yönelik olumlu davranışlarında aktif öğrenmeye dayalı etkinliklerin manidar fark yarattığı bulunmuştur.

Anahtar Sözcükler: Aktif öğrenme, sürdürülebilir çevre tutum, çevre yönelik olumlu davranış, çevreye yönelik olumlu tutum

\begin{abstract}
The research aimed to determine whether active learning-based instruction effects pre-service primary school teachers' sustainable environmental attitudes, positive behaviors and environmental attitudes. The study was carried out with 34 pre-service primary school teachers and data were collected in "Environmental Science and Education" course in the spring semester of 2017-2018 academic year. Also, a monitoring test was carried out in the fall period of 2019-2020. Data were collected with Sustainable Environmental Attitude Scale, Positive Environmental Behavior Scale and Environmental Attitude Scale. The research was carried out with one group pretest-posttest design of weak experimental designs and the data were analyzed in SPSS.22 program. Within the scope of the research, environmental problems were addressed based on the discussions with the candidates, and they were asked to analyze some environmental films and technical trips to the Ecological Building, solar power plant were organized. According to the study, it was found that active learning based activities made positive difference in the teacher candidates' indicated areas towards the environment, make a significant difference in positive behavior towards the environment.
\end{abstract}

Keywords: Active learning, sustainable environmental attitudes, environmental attitudes, environmental positive behaviors

\footnotetext{
${ }^{1}$ Gülfem Muşlu Kaygısız,Dr. Öğr, Üye., Hasan Kalyoncu Üniversitesi, gulfem.muslu@hku.edu.tr
} 
İnsanların, diğer canlılarla yaşamları boyunca ilişkilerini sürdürdükleri ve karşılıklı olarak etkileşim içinde bulundukları ortam olan çevreyle (Önder, Özkan,2013) uyum içerisinde olmaları hayatlarını sağlıklı olarak sürdürmelerine imkân verecektir. Bu uyumun sağlanması da elbette ki çevreye yönelik olumsuz etkilerin azaltılmasıyla mümkün olabilecektir. Çevreye yönelik olumsuz etkilerin azaltılmasında çevre eğitiminin önemi ve gerekliliği kuşkusuzdur. Bozkurt(2009,s.210) çevre eğitiminin, insanın ekolojik çevresini tanımasında ve bu çevredeki yerini kavramasında, yaşadığı gezegenle uyum içerisinde nasıl yaşayabileceğine ilişkin görüşlerini geliştirmesinde ve etkili katılım için gerekli becerilerini kazanmasında rol oynadığını belirtmektedir. Çevre eğitimine yönelik yapılan bazı araştırmalar da bu görüşü desteklemektedir (Deniş, Genç, 2007; Yücel, Işıldar, Yıldırım,2008; Şenel, 2010; Keleş, Uzun, Varnacı Uzun,2010; Roberts vd., 2014; Özdemir, 2010). Çevre eğitiminin etkililiği tüm bireylerle özellikle küçük yaşlardan itibaren çalışmaların yapılmasıyla artırılabilecektir. $\mathrm{Bu}$ nedenle okullara ve dolayısıyla öğretmenlere büyük sorumluluklar düşmektedir. Etkili bir çevre eğitimi için geleceğin öğretmenleri olan öğretmen adaylarının da bu konudaki bilgi, beceri, davranış ve tutumlarının geliştirilmesi gerekmektedir ve bu konuda eğitim fakültelerinin de önemli sorumlulukları vardır. Özellikle eğitim süreçlerinde geleceğin öğretmenlerinin çevreye ilişkin sahip oldukları bilgi ve niteliklerinin geliştirilmesine yönelik yapılan ve yapılacak olan çalışmalar daha sürdürülebilir bir çevre için önemlidir.

Dünya Çevre ve Kalkınma Komisyonu'nun Brundtland Raporunda (1987) sürdürülebilir kalkınma, 'gelecek kuşakların kendi gereksinimlerini karşılamalarını engellemeden bugünün gereksinimlerini karşılamak' olarak tanımlanmaktadır. Çevre eğitimi de sürdürülebilir çevrenin sağlanmasında önemli bir faktör olarak nitelenerek UNESCO (1997) tarafından "Sürdürülebilir Gelecek İçin Eğitim” programıyla ortaya konmuştur. Çevrenin sürdürülebilirliğinin sağlanmasında, bireylerin çevreye yönelik bilgileri kadar tutumları ve davranışları da rol oynamaktadır. Bu nedenle Uzun tarafından (2007, s.20) 'çevre sorunlarından kaynaklanan korku, kızgınlık, huzursuzluk gibi duygularla, değer yargıları ve çevre sorunlarının çözümüne hazır bulunuşluk gibi kişilerin çevreye yararlı davranışlara olan olumlu veya olumsuz tavır ve düşüncelerinin hepsi' olarak ifade edilen çevreye yönelik tutumun kazanılması gereklidir. Ayrıca Yıldız (2011,s.11) tarafından çevrenin canlı ve cansız öğeleriyle bu öğelerin karşılıklı dengesinin varlığının önemine yönelik gösterilen tüm olumlu, olumsuz tepkide bulunma eğilimi olarak tanımlanan sürdürülebilir çevreye yönelik tutum da eğitimciler için geliştirilmesi gereken bir diğer noktadır. Ayrıca Graser (2002) geleneksel çevre eğitim programları yerine sürdürülebilir kalkınma odaklı eğitim programlarının yapılandırmacı öğrenme odaklı olmaları, üretim-tüketim biçimi ve birlikte yaşamı ön planda tutması, sürdürülebilirliğin ekolojik, ekonomik, sosyal ve kültürel boyutlarına odaklı olması nedeniyle tercih edilebilir olarak nitelendirmiştir (Akt. Özdemir,2007). 
Alan yazında çevreye yönelik tutumu inceleyen birçok araştırma bulunmaktadır. Öğretmen adaylarının çevreye yönelik tutumlarını inceleyen birçok araştırmayla birlikte (Kahyaoğlu, Daban, Yangın, 2008; Gürbüz, Çakmak, 2012; Timur,Yılmaz,2013; Doğan, 2013) öğretmen adaylarının geleneksel yöntemlerle işlenen çevre dersiyle çevreye yönelik tutumlarında bir değişiklik oluşturmadığı sonucuna ulaşan araştırmacılar da vardır(Gürbüz, Kışoğlu, Erkol,2007).

Çevreye yönelik olumlu davranışlar, bireyin çevresine karşı gerçekleştirdiği eylemlerin doğaya olan olumsuz etkilerini en aza indirmesi ya da bu eylemleri hiç gerçekleştirmemesi için bilinçli şekilde sergilediği davranışlardır (Kollmuss, Agyeman, 2002). Bireylerin çevrenin korunmasına ve sürdürülebilirliğine yönelik tutumları çevre için önemlidir. Alan yazında çevreye yönelik davranış ve tutum düzeylerine ve bunların kazandırılmasına ilişkin çeşitli çalışmalar bulunmaktadır. Ancak bu çalışmaların genellikle tutum ve davranışları betimsel açıdan incelediği görülmektedir. Bununla birlikte çevreye yönelik tutum ya da davranışların geliştirilmesine yönelik araştırmalar da yapılmıştır. Yapılan çalışmaların sonuçları çevreye yönelik tutum ve davranışların geliştirilmesinde farklı metotların uygulanmasının ve sonuçlarının değerlendirilmesinin önemi ortaya çıkmaktadır. Öğretmen adayları ile sürdürülebilir çevreye yönelik tutumlarının belirlenmesine yönelik yapılan çalışmalarda da benzer şekilde daha çok betimsel değişkenlerin incelendiği görülmektedir (Başaran Uğur, Bektaş, Güneri, 2019; Gürbüz, Çakmak, Derman,2012).

Kalem, Fer'e göre (2003,s.434) öğrencilerin aktif olduğu öğrenme hali aktif öğrenmedir. Öğrenenler bu süreçte zihinsel yeteneklerini kullanarak öğrendikleri bilgilere ilişkin yorum yapmaktadırlar (Süral, 2015). Dolayısıyla aktif öğrenmenin her aşamasında öğrenen merkezdedir ve tüm süreçlerde bilişsel olarak etkindir. Aktif öğrenme bütün öğretim kademelerinde ve Mentiş Taş (2005)'a göre özellikle de öğretmen eğitiminde; öğrenme öğretme ortamlarını deneyimleyerek meslek yaşantılarında kullanmaları için uygulanmalıdır.

Farklı çalışma gruplarıyla gerçekleştirilen araştırmalar aktif öğrenmeyle yapılan öğretimin çevre duyarlılığının ve bilincinin ve ayrıca çevreye yönelik kavramların öğrenilmesinin üzerindeki etkisini ortaya koymaktadır (Aydede Yalçın, 2016; Şenel, 2010; Şahin, Cerrah, Saka, Şahin, 2004). Aktif öğrenmenin özellikleri ve yapılan çalışmaların sonuçları da düşünüldüğünde öğretmen adaylarının çevreye ilişkin bazı yeterliklerinin gelişimine aktif öğrenme merkezli etkinlikler katkı sağlayabilecektir.

\section{Araştırmanın Amacı}

Çevreye yönelik tutum ve davranışların kazanılması bir süreçtir. Burada öğretmenlere çok önemli görevler düşmektedir. Öğretmen adaylarının lisans eğitimleri sürecinde çevre ve öğrencilerin aktif olduğu süreçlerin tasarlanması konularında iyi yetiştirilmeleri gerekmektedir. Buradan hareketle araştırmada aktif öğrenmeye dayalı olarak gerçekleştirilen Çevre Bilim ve Eğitimi dersinin sınıf 
öğretmen adaylarının sürdürülebilir çevreye yönelik tutumlarına, çevreye yönelik olumlu davranışlarına ve çevreye yönelik tutumlarına etkisini belirlemek amaçlanmıştır.

$\mathrm{Bu}$ amaca yönelik olarak şu sorulara yanıt aranmıştır.

“Aktif öğrenmeye dayalı etkinliklerin sınıf öğretmen adaylarının;

1. Çevreye yönelik olumlu davranışları,

2. Çevreye yönelik tutumları,

3. Sürdürülebilir çevreye yönelik tutumları üzerinde etkisi var mıdır?

Varsayımlar ve Sınırlılıklar: Araştırmada katılımcıların ölçeklere samimi yanıt verdikleri varsayılmaktadır. Araştırma araştırmaya katılan öğretmen adayları ile sınırlıdır.

\section{Yöntem}

Araştırmada tek gruplu ön test-son test zayıf deneysel desen kullanılmıştır. Büyüköztürk ve diğ. (2008, s.197)'ne göre zayıf deneysel desenlerde denek temelinde seçkisizlik ve grup eşleştirmesi yoktur. Bu çalışmada kontrol grubu bulunmadığı ve dolayısıyla tek gruplu olduğu, ayrıca çalışma grubu araştırmacının çalıştığı kurumda olduğu ve dolayısıyla temelde seçkisizlik ilkesi uygulanmadığı için zayıf deneysel desen olarak desenlenmiştir.

\section{Çalışma grubu}

Çalışma 2017-18 öğretim yılında Gaziantep'teki bir üniversitenin Eğitim Fakültesinde gerçekleştirilmiştir. Araştırmaya 47 ikinci sınıf, sınıf öğretmen adayı katılmıştır. Ancak toplam 13 öğretmen adayına ait ön test-son test ve izleme testi verileri, eksik veri içermesi vb. nedenlerle değerlendirmeye alınmayarak 34 kişiye ait verilerle araştırma yapılmıştır.

\section{Veri toplama araçları}

Araştırmada sınıf öğretmen adaylarından veri toplamak amacıyla üç farklı ölçek ön test, son test ve izleme testi olarak uygulanmıştır. Adaylara ölçekler, 14 haftalık eğitim süresinin ilk ve son haftalarında, 2017-18 bahar döneminde ön test - son test olarak uygulanmıştır. Ayrıca 2019-2020 öğretim yılı güz döneminde aralık ayında araştırmaya katılan öğretmen adayları ile izleme testi yapılmıştır.

Çevreye Yönelik Olumlu Davranış Ölçeği (DAV): Ölçek Merting(2003) tarafından geliştirilerek Türkçeye Şahin, Ertepınar, Teksöz (2012) tarafından uyarlanmıştır. Ölçek kesinlikle katılıyorumkesinlikle katılmıyorum şeklinde beşli likert tipte 14 maddeden ve tek boyuttan oluşmaktadır. Katılımcıların çevreye yönelik olumlu davranışları ne düzeyde sergilediklerini ölçmek amacıyla kullanılan ölçeğin cronbachs alpha güvenirlik katsayısı 0.86 olarak belirlenmiştir. Yapılan çalışmada ön testte güvenirlik katsayısı 0.76 , son testte 0.83 olarak bulunmuştur. 
Çevreye Yönelik Tutumlar Ölçeği: Thompson ve Barton(1994) tarafından geliştirilen ölçek Uçar, Öztekin(2013) tarafından Türkçeye uyarlanmıştır. Ölçek ekosentrik 10, antroposentrik 13 maddeden oluşmaktadır. Alt boyutlar için cronbach alfa değerleri 0.84 ve 0.78 olarak bulunmuştur. Yapılan araştırmada ise ön testte ve son testte güvenirlik katsayısı sırasıyla ekosentrik alt boyutu için 0.70 ve 0.89 , antroposentrik için 0.73 ve 0.84 olarak hesaplanmıştır.

Sürdürülebilir Çevre Tutum Ölçeği(SÇTÖ): Yıldız (2011) tarafından beşli likert tipte(kesinlikle katılmıyorum/katılıyorum) geliştirilen ölçek 27 maddeden oluşmaktadır. Ölçeğin cronbach alfa değerleri $0.89^{\prime}$ dur. Yapılan araştırmada ise ön testte ve son testte güvenirlik katsayısı 0.89 olarak hesaplanmıştır.

İşlem

Öğretmen adaylarıyla ders kapsamında ilk altı hafta çevre sorunlarının detaylı olarak irdelendiği tartışmaya dayalı ders işlenmiştir. Bu kapsamda '100 Soruda Çevre Sorunu, Çevre Sorunları ve Çevre Politikası'( Keleş,2013) adlı kitap kapsamındaki çevre sorunları öğretmen adayları ile 6 hafta süresince adaylarca yapılan araştırmalarla tartışılmıştır. Adaylar ders kapsamındaki araştırmalarını bireysel olarak gerçekleştirmişlerdir. Araştırma konuları ders öncesinde adaylara verilmiş ve derse gelmeden önce araştırma yapmaları istenmiştir. Ayrıca ders sonrasında da gerekli görülen bazı konularda adaylar ek çalışmalar gerçekleştirmişlerdir. Tartışma sorularının bir kısmı araştırmacı tarafından ders kitabı da göz önüne alınarak hazırlanmış, diğer bir kısmı ise adaylarla yapılan sınıf içi tartışmalarla şekillenmiştir.

7.-12. Haftalar arasında öğretmen adaylarına, daha önce araştırdıkları çevre konuları ile ilişkili bir film listesi sunulmuş ve grup olarak bir film seçerek, ders öncesi izlemeleri istenmiştir. Sunulan film listesinde yer alan filmler belgesel, animasyon film ve sinema filmi niteliğindedir. Adayların film konuları; hidroelektrik santraller ve etkileri, nesli tükenen hayvanlar, nükleer enerji/etkileri, toprak kirliliği, su kirliliği, doğal afetler ve etkileri, geri dönüşüm, çevrenin sürdürülebilirliğidir. Adayların seçtikleri filmlerin çeşidine göre dağılımları da hemen hemen eşittir. Öğretmen adaylarından, filmleri eleştirel bir gözle izlemeleri, içerisinde geçen çevre ile ilgili konu ve kavramları belirlemeleri istenmiştir. Filmlerin incelenmesi sürecinde doldurulması için, araştırmacı tarafından daha önce hazırlanan film değerlendirme raporları öğrencilere verilmiştir. Rapor filmde geçen çevre konu ve kavramları ile ilgili 9 sorudan oluşmaktadır. Film incelemesi ve raporun doldurulmasının ardından, öğretmen adaylarından inceledikleri filmde çevre ile ilgili konuların yer aldığı 12 dakikalık film kesitleri oluşturmaları istenmiştir. Gruplar film kesitlerini ve hazırladıkları raporları sınıf ortamında diğer gruplara sunmuşlar ve konu ile ilgili sınıf tartışmaları yapılmıştır. 
Uygulamanın son iki haftasında öğretmen adayları ile ders kapsamında sürdürülebilirlik konusunda alan gezileri düzenlenmiştir. Alan gezileri sonrasında adaylardan gezilen mekânlarla ilgili rapor hazırlamaları ve mekânlara ilişkin detaylı araştırmalar yapmaları istenmiştir. Bu geziler kapsamında adaylar ilk olarak Ekolojik Bina olarak adlandırılan ve yeşil ev teknolojisi ile tasarlanan binaya götürülmüşlerdir. Bu binada bulunan uzman ve araştırmacı ile ana hatları şekillendirilen üç saatlik bir eğitime katılmışlardır. Bu kapsamda katılımcılara ekolojik bina, tasarımı ve sürdürülebilirliğine ilişkin detaylı bilgiler verilmiştir. Ayrıca küresel ısınma başta olmak üzere çeşitli önemli çevre sorunlarına ilişkin sunu yapılmıştır. Sunuların içeriği temelinde yapılan doğru/yanlış uygulamalar ve sonuçları tartışılmıştır. Öğretmen adayları buradan sonra Botanik Bahçeye götürülmüş ve bitki çeşitliliği, endemik bitkiler, bitkilerin korunmasına ilişkin çeşitli konular tartışılarak buradaki çeşitli özel bitki alanları adayların ilgileri doğrultusunda gezilmiştir. Öğretmen adayları ile son olarak üniversite kampüsü içerisinde bulunan güneş enerjisi santralleri ve çevre analiz laboratuvarı gezilmiştir. Bu geziler öncesinde adaylara uzmanlar tarafından bu alanların tanıtımları ve çalışmalarına ilişkin bilgilerin yanı sıra çeşitli çevreye yönelik kavramlar ve çevre sorunları ve etkileri açıklanmıştır. Geziler kapsamında çevre sorunlarına yönelik konular araştırmacı ve uzmanlarca belirlenen noktalar göz önüne alınarak adaylarla tartışmalar şeklinde irdelenmiştir. Güneş enerji santralinde ve çevre analiz laboratuvarında çevrenin sürdürülebilirliğine ilişkin detaylı tartışmalar veriye dayalı olarak yapılmıştır. Bu merkezlerdeki uygulamalar, yapılan incelemeler ve çevreye etkileri tartışılmıştır. Geziler sonrasında adaylardan merkezlerle ilgili edindikleri deneyimleri, elde ettikleri bilgileri ve uygulamalar hakkındaki görüşlerini içeren bir rapor istenmiştir. Adaylar bu raporlarda merkezlerdeki veriye dayalı sonuçları da tartışmışlar ve gerekli noktalarda bireysel ihtiyaçlarına yönelik araştırmalarını da raporlara yansıtmışlardır.

Tablo 1 öğretmen adayları ile yürütülen aktif öğrenmeye dayalı etkinlik süreci için hazırlanmıştır.

Tablo 1. Araştırma Süreci

\begin{tabular}{|c|c|c|c|c|c|}
\hline 1.HAFTA & 1-6. HAFTA & 7-12. HAFTA & $\begin{array}{l}\text { 13. ve } 14 . \\
\text { HAFTA }\end{array}$ & 14. HAFTA & 2019 Güz \\
\hline $\begin{array}{l}\text { Ön testlerin } \\
\text { Uygulanması }\end{array}$ & $\begin{array}{l}\text { Kaynak } \\
\text { Üzerinden } \\
\text { Çevreye İlişkin } \\
\text { Tartışmalar }\end{array}$ & $\begin{array}{l}\text { Çevre Film } \\
\text { İnceleme } \\
\text { Ödev } \\
\text { Sunumları }\end{array}$ & Alan Gezileri & $\begin{array}{l}\text { Son testlerin } \\
\text { Uygulama }\end{array}$ & $\begin{array}{l}\text { İzleme } \\
\text { testlerinin } \\
\text { uygulama }\end{array}$ \\
\hline
\end{tabular}

\section{Verilerin analizi}

Araştırma kapsamında elde edilen tekrarlı ölçümler arasındaki farkın manidarlığı, ilişkili ölçümler varyans analizi ile incelenmiştir. Analiz öncesinde veri setinde kayıp veri ve uç değer 
bulunup bulunmadığı incelenmiştir. On iki öğrenciye ait ön test verileri, son test ve izleme uygulamalarına katılmadıkları gerekçesiyle analizlere dâhil edilmemiştir. Bir öğrencinin ise toplam puanlar üzerinden hesaplanan standart z puanlarının iki farklı ölçek için $[-3,+3]$ aralığı dışında kaldığ tespit edilmiş ve bu öğrenciye ait veriler de veri setinden çıarılmıştır (Akbaş, Koğar, 2020). Tüm testlerin toplam puanlarına ait aritmetik ortalama, standart sapma, en küçük - en büyük değerler ile çarpıklık ve basıklık katsayıları hesaplanmış; aynı zaman noktasındaki ölçümlere yönelik ilişkiler Pearson Momentler Çarpımı Korelasyon Katsayısı ile incelenmiştir. Mauchly küresellik testi, tekrarlı ölçümler için varyans analizinin küresellik varsayımının karşılandığını göstermiştir (Field, 2018). Tekrarlı ölçümler arasındaki farkın manidar olduğu durumlarda, farkın hangi ölçümler arasında olduğunu bulmak için Sidak çoklu karşılaştırma testinden ve etki büyüklüğünün yorumlanması için kısmi $\eta 2$ değerinden yararlanılmıştır. Etki büyüklüğünün yorumlanmasında 10 için küçük, .25 için orta düzey ve .40 için geniş etki büyüklüğü değerleri dikkate alınmıştır (Cohen, 1992). Tüm analizler için manidarlık düzeyi .05 olarak alınmıştır.

\section{Bulgular}

Araştırma kapsamında ön-son-izleme testi olarak uygulanan ölçeklerden elde edilen puanlara ait betimsel istatistikler Tablo 2'de sunulmuştur.

Tablo 2. Ön test, son test ve izleme testi puanlarına ait betimsel istatistikler $(n=34)$

\begin{tabular}{llrrrrrrr}
\hline Uygulama & \multicolumn{1}{c}{ Ölçek } & \multicolumn{1}{c}{ X } & Ortanca & \multicolumn{1}{c}{ Ss } & Enküçük & Enbüyük & Çarpıklık & Basıklık \\
\hline \multirow{5}{*}{ Ön test } & DAV & 51.85 & 52.00 & 6.97 & 41 & 67 & .52 & -.39 \\
\cline { 2 - 9 } & Ekosentrik & 44.62 & 45.00 & 4.02 & 36 & 50 & -.42 & -.83 \\
\cline { 2 - 9 } & Antroposentrik & 41.91 & 44.00 & 7.22 & 24 & 56 & -.42 & .04 \\
\cline { 2 - 9 } & SÇTÖ & 113.47 & 114.50 & 11.06 & 87 & 135 & -.45 & .19 \\
\hline \multirow{5}{*}{ Son test } & DAV & 54.38 & 56.00 & 6.85 & 41 & 67 & -.26 & -.70 \\
\cline { 2 - 9 } & Ekosentrik & 45.59 & 47.00 & 3.88 & 36 & 50 & -.67 & -.44 \\
\cline { 2 - 9 } & Antroposentrik & 42.94 & 44.50 & 10.70 & 21 & 64 & -.33 & -.28 \\
\cline { 2 - 9 } & SÇTÖ & 115.05 & 116.00 & 12.68 & 81 & 135 & -.63 & .15 \\
\hline \multirow{5}{*}{ İzleme } & DAV & 55.65 & 55.50 & 5.57 & 43 & 65 & -.30 & -.25 \\
\cline { 2 - 9 } & Ekosentrik & 45.35 & 46.00 & 2.97 & 40 & 50 & -.36 & -.76 \\
\cline { 2 - 9 } & Antroposentrik & 44.24 & 45.50 & 9.49 & 25 & 58 & -.51 & -.80 \\
\cline { 2 - 8 } & SÇTÖ & 118.44 & 119.00 & 9.07 & 94 & 132 & -.86 & .64 \\
\hline
\end{tabular}

Tablo 2'de farklı uygulamalar için elde edilen aritmetik ortalama değerlerin ölçeklerden alınabilecek en yüksek puana ve birbirlerine yakın sayılabileceği anlaşılmaktadır. Ek olarak, aritmetik ortalamayla ortanca değerlerinin birbirine yakın olması ve çarpıklık - basıklık katsayılarının $[-1,+1]$ aralığında yer alması birlikte değerlendirildiğinde, tüm ölçümler için puan dağılımının normal kabul edilebileceği anlaşılmaktadır. Ön test, son test ve izleme testi uygulamalarından elde edilen toplam puanlar üzerinden hesaplanan korelasyon katsayıları Tablo 3'de verilmiştir. 
Tablo 3. Ön test, son test ve izleme testi puanları arasındaki korelasyonlar

\begin{tabular}{lcccccccccccc}
\hline \multicolumn{1}{c}{ Ölçek } & \multicolumn{3}{c}{ Ön test } & \multicolumn{4}{c}{ Son test } & \multicolumn{5}{c}{ İzleme testi } \\
1. DAV & 1 & 2 & 3 & 4 & 1 & 2 & 3 & 4 & 1 & 2 & 3 & 4 \\
2. Ekosentrik & 1 & & & & 1 & & & & 1 & & & \\
3.Antroposentrik & .05 & 1 & & & .18 & 1 & & & .30 & 1 & \\
4. SÇTÖ & .12 & .24 & 1 & & -.17 & $.38^{*}$ & 1 & & -.08 & .09 & 1 & \\
\hline
\end{tabular}

${ }^{*} \mathrm{p}<.05,{ }^{* *} \mathrm{p}<.01$

Tablo 3'de, tüm tekrarlı ölçümler için davranış puanları ile ekosentrik ve antroposentrik tutumlar arasında manidar bir ilişkinin söz konusu olmadığı görülmektedir (p>.05). Antroposentrik ile ekosentrik tutum arasında ön test ve izleme testi uygulamalarında manidar bir ilişki görülmezken, son test uygulamasında pozitif ve orta düzey bir ilişkinin söz konusu olduğu $(r=.38, p<.05)$; davranış ile sürdürülebilir tutum arasında ön test $(\mathrm{r}=.62, \mathrm{p}<.01)$ ve son testte $(\mathrm{r}=.66, \mathrm{p}<.01)$ orta düzey ve manidar ilişkinin, izleme testinde manidar olmadığı anlaşılmaktadır ( $\mathrm{r}=.17, \mathrm{p}<.05)$. Tüm ölçüm zamanlarında ekosentrik tutum ile sürdürülebilirlik arasında pozitif ve orta düzey ilişkiler söz konusudur.

DAV, Ekosentrik, Antroposentrik ve STÇÖ puanları üzerinden gerçekleştirilen tekrarlı ölçümler için varyans analizi sonuçlarına göre, davranış ölçeği puanları arasında manidar bir farkın olduğu $(\mathrm{F}(2,66)=7.30, \mathrm{p}<.05)$ fakat Ekosentrik $(\mathrm{F}(2,66)=1,24, \mathrm{p}>.05)$, Antroposentrik $(\mathrm{F}(2,66)=.94, \mathrm{p}>.05)$ ve STÇÖ $(F(2,66)=2.69, \mathrm{p}>.05)$ puanları arasında manidar farkın bulunmadığı görülmüştür.

Manidar farkın söz konusu olduğu davranış ölçeği toplam puanları için gerçekleştirilen Sidak çoklu karşılaştırma testi sonuçlarına göre, ön test ve son test ile son test ve izleme testi puanları arasında manidar bir fark yok iken, ön test ve izleme testi puanları arasında manidar bir farkın olduğu görülmüştür. Davranış puanları için hesaplanan etki büyüklügünün $\eta 2=.18$ olması, bağımsız değişkenin, davranış üzerinde küçük bir etki büyüklüğüne sahip olduğunu göstermektedir.

\section{Tartışma, Sonuç ve Öneriler}

Araştırmanın bulgularına göre aktif öğrenmeye dayalı gerçekleştirilen etkinlikler sınıf öğretmenliği öğretmen adaylarının Sürdürülebilir Çevreye Yönelik Tutum Ölçeği ve Çevreye Yönelik Tutum Ölçeği toplam puanları için ön-test, son-test ve izleme testi puanları arasında manidar fark yaratmamıştır. Ancak Çevreye Yönelik Olumlu Davranış Ölçeği toplam puanları ön test ve izleme testi puanları arasındaki farkların izleme testi lehine manidardır.

Öğretmen adaylarının ön test, son test ve izleme testi puan ortalamaları incelendiğinde tutum ölçeklerinden alınabilecek en yüksek puana yakın değerde puan aldıkları, ölçümler arasında puan ortalamalarında bir miktar artış olsa da bu farkın manidar bir değişiklik oluşturmadığı görülmektedir. Çevreye yönelik tutum ölçeğinde ön testte adayların ekosentrik puan ortalamalarının en yüksek puana yakın bir değer aldığı görülmektedir ve bunda daha önce katıldıkları bazı etkinliklerin etkisi 
olabileceği düşünülmektedir. Ayrıca öğretmen adaylarının antroposentrik puanları da göz önüne alındığında her iki yaklaşıma da sahip adaylar olduğu düşünülmektedir. Tutum geliştirme sürecinin uzun vadeli bir süreç olduğu düşünülürse ön test ve son test arasında bir fark oluşmasa da ön test ve izleme testi arasında aktif öğrenme sürecinin fark yaratması beklenmektedir. İzleme testinde ayrıca ekosentrik puanlarda artma, antroposentrik puanlarda ise azalma beklenmektedir. Ancak yapılan teste her iki alt boyut için de az da olsa puan artışı olduğu görülmektedir. Bu duruma antroposentrik tutumlara ilişkin maddelerin adaylar tarafından tam olarak anlaşılmamasının neden olabileceği düşünülmektedir. Ayrıca araştırmada beklenen sonuca, belirtilen puan ortalamaları nedeniyle de ulaşılamadığı düşünülmektedir. Alan yazında yapılan bazı araştırmalarda (Kahyaoğlu, Daban, Yangın, 2008; Erol, Gezer, 2006) araştırma bulgularını destekler nitelikte çevre dersini alan öğretmen adaylarının çevre tutumlarında değişiklik olmadığı bulunmuştur. Ancak Ek vd.(2009) araştırmalarında çevre dersi alınmasının tutum üzerinde anlamlı farklılık yarattığını saptanmışlardır. Sınıf öğretmen adaylarının çevreye yönelik tutumlarını Genç, Genç (2013) yüksek; Çimen, Benzer (2019) ise araştırmalarında sürdürülebilir çevreye yönelik tutumlarının yüksek olduğunu bulmuşlardır. Ayrıca sınıf düzeyleri bazında 2.-4. sınıflar arasında fark olduğunu belirtmişlerdir. Başaran Uğur, Bektaş, Güneri(2019) sürdürülebilir çevreye yönelik sınıf öğretmen adaylarının tutumlarının orta düzeyde olduğunu bu araştırmaya benzer şekilde ortaya koymuştur. Yapılan bu araştırmayla sürdürülebilir tutum puanlarının aktif öğrenme merkezli etkinliklerle arttığı görülmektedir. Bu sonuca özellikle alan gezilerinin etkili olduğu da düşünülmektedir.

Öğretmen adaylarının Çevreye Yönelik Olumlu Davranış Ölçeği puanları incelendiğinde aktif öğrenme temelli etkinliklerin ön test ve izleme testi arasında manidar fark yarattığ 1 görülmektedir. Davranış geliştirme sürecinin de tutum gibi uzun vadeli bir süreç olduğu düşünüldüğünde iki ölçüm arasında manidar fark olması beklenmektedir ve araştırma sonuçları da bunu desteklemektedir. Uçar(2015,s.21) çevresel davranışlar ve tutumlar arasında yapılan araştırmaların, tutumların davranışları yordadığını gösterdiğini ancak değişkenler arasındaki ilişkinin genellikle zayıf ve orta derecede ilişkili olduğunu belirtmiştir. Bu sonuç yapılan araştırmada öğretmen adaylarının çevreye yönelik davranışlarında aktif öğrenmeye dayalı etkinliklerin fark yarattığını ancak benzer sonucun tutumlar da görülmemesinin nedenini açıklayabilmektedir. Öğretmen adaylarıyla yürüttükleri araştırmalarda Şenel (2010), Şahin, Cerrah, Saka ve Şahin (2004), Kaygısız, Benzer, Eren(2019) aktif öğrenme temelinde gerçekleştirilen çevre derslerinin çevre bilinci gelişimi ve çevre eğitimi öz yeterliğine katkı sağladığı bulunmuştur. Araştırmada Çevreye Yönelik Olumlu Davranış Ölçeğinde ön test ve son test arasında manidar bir fark oluşmazken ön test ve izleme testi arasında fark oluşmuştur. Kaygısız, Benzer, Eren (2019)'in aktif öğrenmeye dayalı etkinliklerin çevreye yönelik davranış 
üzerindeki etkisini inceledikleri araştırmalarında ön test ve son test puanları arasında benzer şekilde manidar fark oluşmamıştır.

Araştırmada ekosentrik tutumlar ile sürdürülebilir çevreye yönelik tutum arasında pozitif ve orta düzey ilişki olduğu bulunmuştur. Barr'ın (2003) araştırmasında da benzer şekilde ekosentrizm ile sürdürülebilirlik arasında anlamlı bir ilişki olduğunu bulmuştur. Ön test ve son test puanlarına göre sürdürülebilir çevreye yönelik tutum ve davranış arasındaki olumlu ilişkiye aktif öğrenme merkezli çevre eğitimi uygulamalarının etkili olduğu görülmektedir.

Araştırma sonuçlarına göre araştırmacılara çevreye yönelik tutum ve davranışlar arasındaki ilişkileri niteliksel olarak belirlemeye yönelik araştırmalar yapmaları önerilebilir. Sürdürülebilir çevreye yönelik öğretmen adaylarının tutum ve davranışlarında aktif öğrenme merkezli etkinliklerin etkili olmasından hareketle antroposentrik tutumlarını azaltacak başka çalışmalar da planlanabilir. Ayrıca izleme testi sonuçlarından hareketle uzun vadede sürdürülebilir tutum ve davranışların etkisinin zayıflaması göz önüne alınarak kalıcı etki yaratabilecek çevresel uygulamalar yapılabilir.

\section{Kaynaklar}

Akbaş, U., ve Koğar, H. (2020). Nicel Araştırmalarda Kayıp Veriler ve Uç Değerler: Çözüm Önerileri ve SPSS Uygulamaları. Pegem Akademi: Ankara.

Aydede Yalçın,Y.,M,N. (2016). The Effect Of Active Learning Based Science Camp Activities on Primary School Students' Opinions Towards Scientific Knowledge and Scientific Process Skills. International Electronic Journal of Environmental Education, 6(2),108-125.

Barr,S.(2003).Strategies For Sustainability: Citizens and Responsible Environmental Behaviour. Area, 35(3), 227-240.

Başaran Uğur,R.,Bektaş,O.,Güneri,E.(2019). Clasroom and Science Teachers' Sustainable Environment Attitude Levels.The Journal of International Social Research.12(63),775-788.

Bozkurt, O. (2009). Çevre Ĕ̆̆itimi, Editör: Aydoğdu, M., Gezer, K. Çevre Bilimi (4.Baskı). Anı Yayıncılık: Ankara.

Bruntland, G. (ed.), (1987), Our common future: The World Commission on Environment and Development, Oxford, Oxford University Press. https://sswm.info/sites/default/files/reference_attachments/UN\%20WCED\%201987\%20Brundtl and\%20Report.pdf

Büyüköztürk, Ş., Çakmak, E., Akgün, Ö. E., Karadeniz, Ş. ve Demirel, F. (2008). Bilimsel Araştırma Yöntemleri (2. Baskı). Pegem Akademi: Ankara.

Cohen, J. (1992). A power primer. Psychological Bulletin, 112(1), 155-159. 
Deniş, H. ve Genç, H. (2007). Çevre Bilimi Dersi Alan Ve Almayan Sınıf Öğretmenliği Öğrencilerinin Çevreye İlişkin Tutumları ve Çevre Bilimi Dersindeki Başarılarının Karşılaştırılması. Mehmet Akif Ersoy Üniversitesi Ĕ̆itim Fakültesi Dergisi, 13, 20-26.

Doğan,E.E. (2013). Knowledge Levels and Attitudes of Prospective Teachers and Biologist Candidates towards the Environment. Illköğretim Online, 12(2), 413-424.

Ek, H. N., Kılıç, N., Öğdüm, P., Düzgün, G., Şeker, S. (2009). Adnan Menderes Üniversitesinin Farklı Akademik Alanlarında Öğrenim Gören İlk ve Son Sınıf Öğrencilerinin Çevre Sorunlarına Yönelik Tutumları Ve Duyarlılıkları. Kastamonu Ĕ̆itim Dergisi, 17(1), 125-136.

Erol, G. H., Gezer, K. (2006). Sınıf Öğretmenliği Öğretmen Adaylarının Çevreye ve Çevre Sorunlarına Yönelik Tutumları. Journal of Environmental and Science Education, 1(1), 65 - 77.

Field, A. (2018). Discovering statistics using IBM SPSS Statistics (5. Ed.). Sage.

Genç,M.,Genç,T.(2013). Sınıf Öğretmenliği Öğrencilerinin Çevreye Yönelik Tutumlarının Belirlenmesi. Asya Öğretim Dergisi, 1(1), 9-19.

Gürbüz,H., ,Çakmak,M.,Derman,M. (2012). Biyoloji Öğretmen Adaylarının Sürdürülebilir Çevreye Yönelik Tutumları. Türk Bilimsel Derlemeler Dergisi, 6(1), 144-149.

Gürbüz,H., ,Çakmak,M. (2012). Biyoloji Eğitimi Bölümü Öğrencilerinin Çevreye Yönelik Tutumlarının İncelenmesi. Dicle Üniversitesi Ziya Gökalp Ĕ̆itim Fakültesi Dergisi, 19,162-173.

Gürbüz,H., Kışoğlu,M., Erkol,M.(2007). Biyoloji Öğretmen Adaylarının Çevreye Yönelik Tutumlarının İnformal Ve Formal Eğitim Ortamları Açısından Değerlendirilmesi. A.Ü. Bayburt Eğitim Fakültesi Dergisi, 2(3), 74-84.

Kahyaoğlu, M., Daban, Ş., Yangın, S. (2008). İlköğretim Öğretmen Adaylarının Çevreye Yönelik Tutumları. D.Ü.Ziya Gökalp Eğitim Fakültesi Dergisi, 11, 42-52.

Kalem, S., Fer, S. (2003). Aktif Öğrenme Modeliyle Oluşturulan Öğrenme Ortamının Öğrenme, Öğretme Ve İletişim Sürecine Etkisi. Kuram ve Uygulamada Eğitim Bilimleri,3(2), 433-461. http://eds.a.ebscohost.com/eds/detail/detail?vid=0\&sid=0904feb2-aa9e-40d4-a6db-

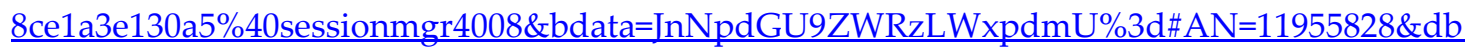
$=\underline{a 9 h}$

Keleş,R. (2013). 100 Soruda Çevre, Çevre Sorunları ve Çevre Politikası (1. Baskı), Yakın Yayınları: Ankara. Keleş, Ö, Uzun,N., Varnacı Uzun, F. (2010). Öğretmen Adaylarının Çevre Bilinci, Çevresel Tutum, Düşünce Ve Davranışlarının Doğa Eğitimi Projesine Bağlı Değişimi ve Kalıcılığının Değerlendirilmesi. Elektronik Sosyal Bilimler Dergisi,9(32), 384-401.

Kollmuss,A., Agyeman,J. (2002). Mind the Gap: Why Do People Act Environmentally and What Are the Barriers to Pro-Environmental Behavior? Environmental Education Research,. 8(3),239-260. 
Mentiş Taş, A. (2005). Öğretmen Eğitiminde Aktif Öğrenme. Gazi Üniversitesi Kırşehir Eğitim Fakültesi Dergisi, 6(2), 177-184

Muşlu Kaygısız,G., Benzer, E.,Dilek Eren, C.(2019). Aktif Öğrenmeye Dayalı Etkinliklerin Okul Öncesi Öğretmen Adaylarının Çevre Etiği Farkındalığı, Çevre Davranışı ve Çevre Eğitimine İlişkin Özyeterliklerine Etkisi. Marmara Üniversitesi Atatürk Eğitim Fakültesi Eğitim Bilimleri Dergisi, 50 (50) , 125-141.

Önder,A.,Özkan,B.(2013). Sürdürülebilir Çocuk Gelişimi Okul Öncesinde Etkinliklerle Çevre Ĕ̆itimi. (1. Baskı) Anı Yayıncılık: Ankara.

Özdemir,O. (2007). Yeni Bir Çevre Eğitimi Perspektifi: “Sürdürülebilir Gelişme Amaçlı Eğitim. Eğitim ve Bilim, 32(145), 23-39.

Özdemir,O. (2010) Doğa Deneyimine Dayalı Çevre Eğitiminin İlköğretim Öğrencilerinin Çevrelerine Yönelik Algı ve Davranışlarına Etkisi. Pamukkale Üniversitesi Eğitim Fakültesi Dergisi, 27(27), $125-138$.

Roberts, P.,Downes,N., Cooke,L., Heiner,I., Caffery,J. (2014). Education, Place and Sustainability: A Literature Review and Overview of Curriculum and Policy in the States and Territory of the Murray Darling Basin https://www.researchgate.net/publication/271446190 Education place and sustainability a li terature review and overview of curriculum and policy in the states and territory of th e Murray-Darling Basin

Sahin,E.,Ertepinar,H.,Teksoz,G. (2012).University Students' Behaviors Pertaining To Sustainability: A Structural Equation Model With Sustainability-Related Attributes. International Journal of Environmental and Science Education, 3(3),459-478.

Süral, S.(2015). Öğretmen Adaylarının Aktif Öğrenmeye Yönelik Algılarının Farklı Değişkenler Açısından İncelenmesi. KSBD, Hüseyin Hüsnü Tekışık Özel Sayısı, 2(7), 31-49.

Şahin,N.F., Cerrah,L.Saka,A.,Şahin,B.(2004). Yükseköğretimde Öğrenci Merkezli Çevre Eğitimi Dersine Yönelik Bir Uygulama. GÜ, Gazi Ĕ̆itim Fakültesi Dergisi, 24(3), 113-128.

Şenel,H (2010) Fen Bilgisi Öğretmen Adaylarının Çevre Bilincinin Geliştirilmesinde Probleme Dayalı Aktif Öğrenmenin Etkisi.(Yayımlanmamış yüksek lisans tezi). Balıkesir Üniversitesi, Balıkesir.

Timur, S., Yılmaz, M. (2013). Çevre Davranış Ölçeğinin Türkçe’ye Uyarlanması. Gazi Üniversitesi Gazi Ĕ̆itim Fakültesi Dergisi, 33(2), 317-333.

Uçar,M.B.,Öztekin,C.(2013). A Study on Pre-service Science Teachers' Value Orientations:Predictive Influences of Enviromental Identity,Gender Identity and Ecological Worldview. Poster 
Presented at the International Perspectives on New Aspects of Learning in Teacher Education Conference.Diyarbakır,Turkey.

Unesco (1997) Educating For A Sustainable Future: A Transdisciplinary Vision For Concerted Action. http://www.unesco.org/education/tlsf/mods/theme_a/popups/mod01t05s01.html

Uzun, N. (2007). Ortaöğretim öğrencilerinin çevreye yönelik bilgi ve tutumları üzerine bir çalışma. Yayımlanmamış Doktora tezi. Hacettepe Üniversitesi, Fen Bilimleri Enstitüsü, Ankara.

Yıldız, Ş. (2011). Öğretmenlerin, Öğretmen Adaylarının Ve Öğrencilerin Sürdürülebilir Çevre İle İlgili Kavramsal Anlamaları Ve Tutumları. Yayımlanmamış yüksek lisans tezi, Dokuz Eylül Üniversitesi, Eğitim Bilimleri Enstitüsü.

Yücel Işıldar, G.(2008). Meslek Yüksekokulları Boyutunda “Çevre Eğitimi'nin Çevreci Yaklaşımlar ve Davranışlar Üzerindeki Etkilerinin Değerlendirilmesi. Türk Ĕ̆itim Bilimleri Dergisi,6(4), 759778.

Yücel Işıldar,G., Yıldırım,F. (2008). The Effectiveness of Environmental Education on Environmentally- Sensitive Behaviors. Education and Science,33(148), 13-25.

\section{ORCID}

Gülfem Muşlu Kaygısız iD https://orcid.org/0000-0003-3286-0454

\section{Extended Summary}

\section{The Effect Of Active Learning Based Activities On The Sustainable Environmental Attitudes, Positive Behaviors And Environmental Attitudes Of Primary School Teacher Candidates}

Environmental education enables people to recognize their ecological environment, to understand their place, to develop an understanding of how they can live in harmony with the planet they live in and to acquire the skills necessary for effective engagement (Bozkurt, 2009). Some research on environmental education also supports this view (Deniş, Genç, 2007; Yücel, Işıldar, Yıldırım, 2008; Yücel Işıldar 2008; Şenel, 2010, Keleş, Uzun, Varnacı Uzun, 2010; Özdemir, 2010, Roberts et al., 2014). In order to increase the effectiveness of environmental education, it is important to carry out studies for all individuals, especially from young ages. For an effective environmental education, the knowledge, skills, behaviors and attitudes of pre-service teachers, need to be developed and thus education faculties have also important duties in this regard. In the literature, there are many studies (Kahyaoğlu, Daban,Yangın,2008; Gürbüz, Çakmak, 2012; Timur,Yılmaz, 2013; Doğan, 2013) examining the pre-service teachers attitude towards the environment. Some studies conducted with different sample groups show that active learning has an effect on various variables related to environment such as environmental awareness, consciousness and teaching environmental concepts (Aydede Yalçın, 2016; Şahin et.al, 2004; Şenel, 2010). Considering all these factors, it is thought that active 
learning oriented activities can contribute to the development of prospective teachers' some competencies related to environment.

The research aimed to determine the effect of "Environmental Science and Education" course which is conducted based on active learning on the attitudes of the primary school teacher candidates' towards sustainable environment, positive behaviors towards the environment and attitudes towards the environment. For this purpose, the following questions were examined.

Do activities based on active learning have an effect on the primary school teacher candidates';

1- Positive behaviors towards the environment?

2- Attitudes towards the environment?

3- Attitudes towards the sustainable environment?

\section{Method}

In the study, one group pretest-posttest design which is one of the weak experimental designs was used.

\section{Study Group}

The study was carried out with 47 prospective primary school teachers who were studying in the second grade of a university in Gaziantep in 2017-2018 academic year. But the analysis was conducted with 34 prospective primary school teachers due to missing data.

\section{Tools}

In the research, three separate scales were applied as pre/post/monitoring-test to obtain data. The scales were administered to prospective teachers at the beginning and end of the 14-week intervention period and monitoring test was applied in 2020 spring semester. Environmentally Positive Behavior Scale(EPBS) originally developed by Merting (2003) and adapted to Turkish by Şahin, Ertepınar and Teksöz (2012). Environmental Attitudes Scale (EAS) developed by Thompson, Barton (1994) was adapted to Turkish by Uçar, Öztekin (2013) and consists of 10 ecocentric, 13 anthropocentric items. Sustainable Environmental Attitude Scale(SEAS) was developed by Y1ldiz(2011).

\section{Process}

Within the scope of the lesson, firstly, the controversial lesson based on the discussion of the environmental problems in detail was taught with the book. Later, the teachers watched the various environmental films that the candidates determined from a list of films recommended by the 
researcher. Environmental issues and concepts in the film were critically examined and discussed with other candidates in the classroom for six weeks. Field trips were organized with prospective teachers within the scope of the lesson. After the field trips, the candidates were asked to prepare reports.

\section{Data Analyses}

The significance of the difference between the repeated measurements obtained within the scope of the research was examined by analysis of variance for related measurements. Arithmetic mean, standard deviation, minimum-maximum values, and skewness and kurtosis coefficients of the pre/post/monitoring-test total scores were calculated. The relationships between the measurements obtained at the same time point were examined with the Pearson Moments Product Correlation Coefficient. In cases where the difference between repeated measurements is significant, Sidak multiple comparison test was used. For all analyzes, .05 was taken as the level of significance.

\section{Results}

Descriptive statistics of the scores obtained from the scales applied as pre/post/monitoring-test shows that the arithmetic mean values can be counted closest to each other with the highest score that can be obtained from the scales. The correlation coefficients calculated from the total scores obtained from the pre/post/monitoring-test applications do not seem to have a significant relationship between the behavioral scores and the echocentric and anthropocentric attitudes for all repeated measurements. While there is no significant relationship between anthropocentric and echocentric attitude in the pretest and monitoring- test applications, there is a positive and medium level relationship in the post-test application $(\mathrm{r}=.38, \mathrm{p}<.05)$; In the pre-test $(\mathrm{r}=.62, \mathrm{p}<.01)$ and post-test $(\mathrm{r}=.66, \mathrm{p}<.01)$ between EPBS and SEAS, it is understood that the significant relationship is not significant in the follow-up test $(r=.17$, $\mathrm{p}<.05)$. At all measurement times, there are positive and moderate relationships between ecocentric attitude and SEAS. According to the results of the variance analysis for repeated measures performed on the EPBS, Echocentric, Anthropocentric and SEAS scores, there was a significant difference between the scores of the behavioral scale $(\mathrm{F}(2.66)=7.30, \mathrm{p}<.05)$ but there was no significant difference between Echocentric $(\mathrm{F}(2.66)=1.24, \mathrm{p}>.05)$, Anthropocentric $(\mathrm{F}(2.66)=.94, \mathrm{p}>.05)$ and SEAS $(\mathrm{F}(2.66)=2.69, \mathrm{p}>.05)$ scores. According to the results of Sidak multiple comparison test conducted for EPBS total scores with significant difference, there was a difference between pre-test and monitoring-test scores. The effect size indicates that the independent variable has a small effect size on the EPBS.

\section{Discussion, Conclusion and Suggestions}

When the pre/post/monitoring-test average scores of the teacher candidates are examined, it is seen that there is a slight increase in the mean score between the measurements, although this 
difference does not constitute a significant change between the measurements. In some researches conducted in the literature (Kahyaoğlu, Daban, Yangın, 2008; Erol, Gezer, 2006), it was found that there is no change in the environmental attitudes of the pre-service teachers who take the environmental lesson that supports the research findings. However, Ek et al. (2009) was found that taking environmental lessons creates a significant difference on attitude. Genç, Genç (2013) found preservice teachers' attitudes towards environment are high; Başaran et.al (2019) have a moderate attitude towards sustainable environment; Çimen, Benzer(2019) found that their attitudes towards sustainable environment are high in their researches.

When the positive environmental behavioral scale scores of teacher candidates are examined, it is seen that the activities based on active learning make a significant difference between the pre-test and the monitoring-test. Uçar $(2015,21)$ stated that research conducted between environmental behaviors and attitudes show that attitudes predict behavior, but the relationship between variables is generally weak and moderately related. This result may explain the study's result. In the research conducted by Şenel (2010) and Şahin et.al (2004) with teacher candidates, was found that environmental lessons conducted with active learning contributed to the development of environmental awareness. In the research, there was a difference between the pre-test and monitoringtest on the EPBS. There was no significant difference between pre-test and post-test scores in the researches that Muşlu Kaygisız,Benzer, Eren (2019) examined the effects of active learning based activities on environmental behavior.In the research, a positive and medium level relationship was found between echocentric attitudes and attitudes towards sustainable environment similarly with Barr's (2003) study.

Based on the findings, researches that examine the qualities of the pre-service teachers' actions performed in active learning processes can be planned. 